\title{
Equipment design for biosorption studies with microorganisms
}

\author{
Thomas E. Jensen \\ Department of Biological Sciences \\ Lehman College \\ City University of New York \\ 250 Bedford Park Boulevard West, Bronx \\ NY 10468, USA \\ Tel: 7189608235 \\ Fax: 7189608236 \\ E-mail: dolores.vitanza@lehman.cuny.edu \\ Mary C. Crang \\ Trauma Unit \\ Loyola University Medical Center \\ 2160 S. First Ave., Maywood \\ IL 60153, USA \\ Tel: 7083273717 \\ Fax: 7083272818 \\ E-mail:mhitt@lumc.edu \\ Richard F.E. Crang* \\ Department of Plant Biology \\ University of Illinois at Urbana-Champaign \\ 505 S. Goodwin Ave., Urbana \\ IL 61801, USA \\ Tel: 2173330616 \\ Fax: 2172447246 \\ E-mail: r-crang@life.uiuc.edu
}

Financial support: This work was funded in part by a grant from the Research Foundation of the City University of New York and NIH SCORE grant \#5S06GM008225-22.

Keywords: bead maker, biosorption, flow-cell, sodium alginate.

Abbreviations: ICP: Inductively Coupled Plasma

Two laboratory devices have been designed for experimental use in biosorption studies involving the uptake and controlled release of elements from encapsulated living cells of microorganisms. The first device is an alginate bead maker capable of producing uniform (1.5 mm diameter) sodium alginate beads with encapsulated microorganisms. The second device is a flow-cell that can subject the encapsulated microorganisms to changing fluids, streaming gaseous microaerophyllic conditions, and which also allows for samples of fluid and beads to be extracted at any time during changing experimental conditions. Both devices are novel and simple in their design, and enable improved accuracy and precise handling of encapsulated specimens with minimal labour and expenditure.

Following the early success of Murashige and Skoog (1962) in obtaining tobacco tissue culture growth, researchers have utilized a variety of technical approaches in the encapsulation of individual or clusters of living cells (Bashan, 1986), and their experimental handling for the uptake and release of varied compounds, as well as heavy metals (Wilde and Benemann, 1993). Many research efforts have aimed at producing biological cells in an "immobile" form through the process of embedding living cells in sodium alginate beads, which are porous enough for the exchange of various fluid substances that are life supporting as well as experimental in nature. The production of uniform size and composition alginate beads has been employed for some time by multiple researchers for a variety of purposes including the encapsulation of: bacteria (Lee and Heo, 2000), pancreatic and other mammalian cells (Heald et al. 1994), hemoglobin (Huguet et al. 1994), a variety of algae and cyanobacteria (Gonzalez and Bashan, 2000) as well as plant microshoots (Previati et al. 2005) and somatic plant embryos.

Some of these applications require beads of a specific size in order to accommodate larger specimens, but most utilize a standard of approximately 1-1.5 mm diameter beads. In most protocols, exuding droplets of sodium alginate into a calcium chloride $\left(\mathrm{CaCl}_{2}\right)$ solution solidifies the alginate and produces beads. Many factors determine the size and

*Corresponding author 


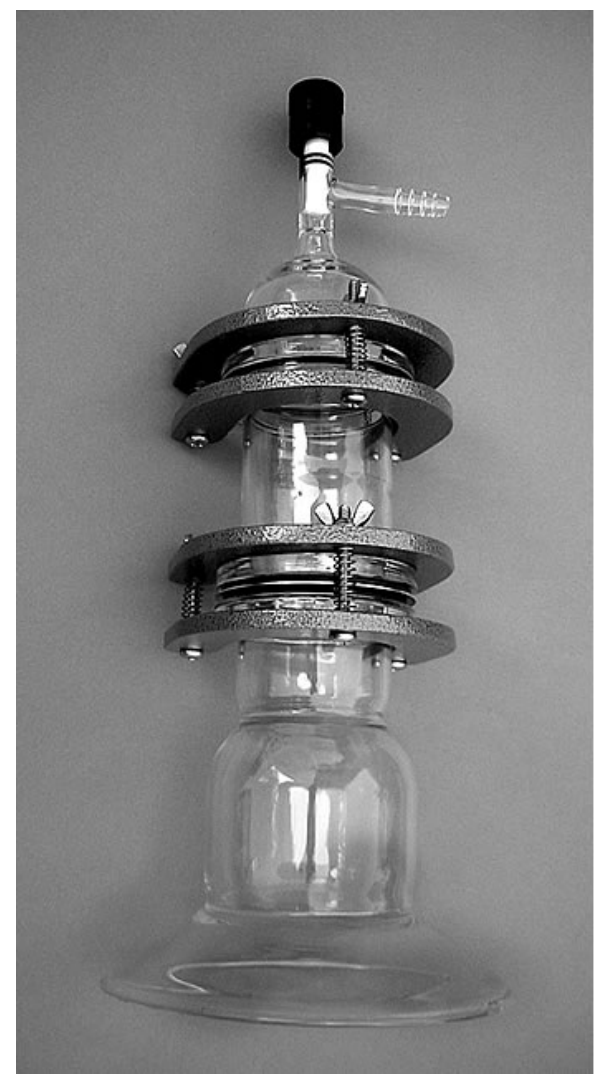

Figure 1. Fully assembled bead-maker with glass parts separated by rubber O-rings and held together by threepoint adjustable horseshoe clamps.

hardness of the beads including: the size of the pores through which the sodium alginate is exuded, the concentration of the sodium alginate as well as that of the $\mathrm{CaCl}_{2}$, the length of time in which the exuded beads remain within the calcium chloride solution, and physical or electrostatic forces that may be used to drive the extrusion of the beads (Serp et al. 2000; Klokk and Melvik, 2002).

Herein, we report on the design of two laboratory devices that provide reliable and reproducible results for a variety of experimental purposes involving the production and experimental use of encapsulated organisms as in the biosorption of cations and heavy metals. First, it is important to have a device that will produce uniform size beads of sodium alginate into which cells are encapsulated. As with most methods, we utilize extrusion of the alginate containing living cells into an external gelation fluid. Following this, a reaction vessel, hereafter referred to as a flow-cell, may be utilized with a means of introducing fluids that can bathe a mass of experimental alginate beads, as well as to subject them to different levels of oxygenation. We describe a relatively simple but unique design of these two laboratory devices, their operational features and some potential research applications. Both devices are designed to be autoclaved as needed.

\section{MATERIALS AND METHODS}

\section{Alginate bead-maker}

We have designed a bead-maker that is simple and relatively inexpensive in construction, capable of working with small (approx. $30 \mathrm{ml}$ ) volumes of liquid alginate containing cellular suspensions, and giving reproducible results. The assembled unit is shown in Figure 1 and stands approx. $40 \mathrm{~cm}$ high with a basal circumference of approx. $12.5 \mathrm{~cm}$. It is comprised of three Pyrex ${ }^{\circledR}$ glass components separated by O-rings and a porous aluminium grid, and held together by two horseshoe clamps. Figure 2 shows the individual components in an exploded view that allows for better distinguishing their features. Figure 3 illustrates a pair of aluminium disks showing both surfaces in which $\mathrm{A}$ $=$ top and $\mathrm{B}=$ bottom surface. The depression wells each have an approx. $1 \mathrm{~mm}$ diameter opening with a bevelled edge after that as described by de-Bashan et al. (2003).

\section{Flow-cell}

The flow-cell is a multi-piece Pyrex ${ }^{\circledR}$ glass compartment in which alginate beads with encapsulated cells are contained in a bath of nutrients or other fluids, and in which the air quality can be modified as desired through the introduction of other gasses as desired for experimental purposes. As shown in Figure 4a, the uppermost piece of the flow-cell has a standard hose connector for the attachment of a feeder line of solutions (gravity fed) that may be used in the experimental processes. It is connected to the main central unit using an O-ring and a standard horseshoe clamp with three tightening screws. This central unit also possesses a sidearm with a Teflon ${ }^{\circledR}$ shutoff valve, and a female fitting for the attachment of a standard Leur-loc ${ }^{\circledR}$ syringe that enables the extraction of samples from the specimen chamber during operations. The central unit, in turn, is connected to a lower assembly by means of another standard horseshoe clamp and with another O-ring. The lower unit possesses a Teflon ${ }^{\circledR}$ shutoff valve and a hose connector for the attachment of another plastic hose line that may be used for releasing solutions, or for the introduction of an upwards flow of dry $\mathrm{N}_{2}$ gas through the experimental chamber. When the lower valve is closed, the volume capacity of the entire flow-cell unit assembly is 300 $\mathrm{ml}$. Figure $4 \mathrm{~b}$ illustrates an expanded view of selected parts of the flow-cell assembly.

An optional adaptor has been designed to fit into the central unit prior to its assembly that restricts the total internal volume capacity of the flow-cell to $50 \mathrm{ml}$ (Figure 5). It is comprised of a Pyrex ${ }^{\circledR}$ glass cylinder sealed at both ends, and with a slotted base unit that allows for the nonobstructive flow of fluids and beads. Clearly, insert adaptors of other sizes can be fabricated by glassblowing with minimal cost and effort, making the flow-cell more versatile in working with experimental materials contained in varied volumes. 


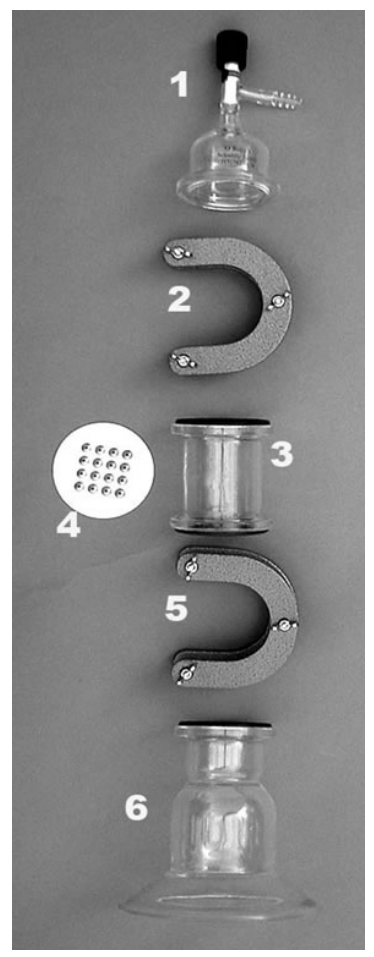

Figure 2. A disassembled bead-maker showing all the component parts.

1) Top unit with side-arm to which a hand-held bulb-type air pump and gauge can be attached for pressure regulation as needed. Above the side-arm is a plastic adjustable valve that can aid in regulating air pressure, sealing the system from the pump, and allowing for backfilling of air or other gas when pump has been removed.

2) The upper three-point adjustable horseshoe clamp for holding units 1 and 3 together.

3) This unit serves as the reservoir for the fluid sodium alginate with mixed cellular material(s). The unit shown here has an approx. 50 $\mathrm{ml}$ solution capacity, but is intended to be used with approx. $30 \mathrm{ml}$ samples. The height of this unit can be varied to accommodate larger volumes as needed. Note that top and bottom O-rings are shown in place.

4) An aluminium separation plate with pores for the flow of sodium alginate-specimen mixture. Through these pores, the droplets of the mixture fall into a $\mathrm{CaCl}_{2}$ solution below.

5) The lower three-point adjustable horseshoe clamp for holding units 4 and 6 together, and with the porous separation plate inbetween, held by O-rings on each of the glass units.

6) The bottom unit serving as a receptacle for the alginate-specimen droplets that fall into a contained $\mathrm{CaCl}_{2}$ solution. The bottom part of the unit is bevelled outwards to provide a self-supporting stand for the assembled system. A solid glass bottom is above the expanded stand, and is also accessible from the inside for easy cleaning.

\section{System use and construction}

Beads containing varied encapsulated substances or living cells are collected in a bath of calcium chloride solution and, typically within $30 \mathrm{~min}$, are washed free of the $\mathrm{CaCl}_{2}$ solution in distilled water (3x) for 10 min each with gentle stirring. The beads are then transferred to the flow-cell containing an experimental medium that may be stationary, flowing, gas charged or with continuous changeable solutions as dictated by experimental protocol.

Construction of all glassware components was fabricated at: O’Brien Glassblowing, 750 Railroad, P.O. Box 495, Monticello, IL 61856, USA. The aluminium filter plates for both the alginate bead-maker and the flow-cell were made at: IFab Precision Prototyping, 1821 S. Oak St., Champaign, IL 61820, USA.

\section{RESULTS AND DISCUSSION}

Alginate beads for experimental purposes have commonly been made manually through expulsion from a needle-less syringe, one at a time, using a simple dropper method. While adequate in many circumstances, the technique is very rudimentary, time-consuming and prone to considerable variation in bead size and shape. One of the more effective devices for producing large quantities of beads has been through the use of a gravity-flow system that was designed by de-Bashan et al. (2003); however, the unit they originally conceived required up to $500 \mathrm{ml}$ solution, and the early drops that were intended to form beads often developed in the form of elongated strings, as well as those of the final ones produced when the level of fluid became low. Only those beads formed during the midrange of alginate flow were found to be uniform in size and shape. Also, it was often difficult to obtain enough 


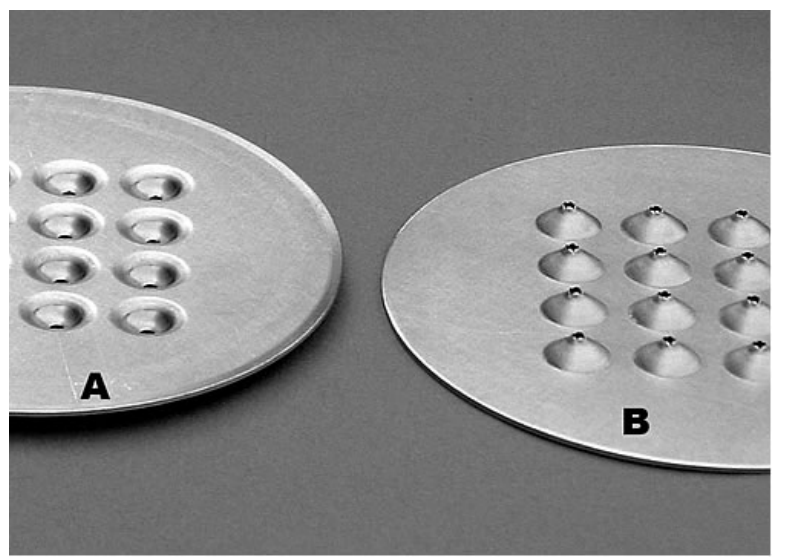

Figure 3. Aluminium filter plates with 16 indentationperforations showing upper surface with depressions (a), and the lower surface (b) with $1 \mathrm{~mm}$ diameter bevelled openings.

microbiological specimen cultures to prepare adequately loaded beads for experimental use when dealing with volumes over $100 \mathrm{ml}$. The bead maker described herein has been designed with a capacity of $30 \mathrm{ml}$, which allows for uniform bead formation, and an alginate/specimen slurry can be easily refilled into the unit before the last beads have moved through the filter plate.

Beads along with their experimental solution (e.g. growth medium) are then quickly loaded into the flow-cell chamber with the top unit removed, and then the devise is assembled with attachment of a hose to the top unit. Regulation of the valve on the lower unit allows for the continuous flow of fluids, or their retention. For continuous recycling purposes, the use of a peristaltic pump on the effluent hose line can reintroduce the solutions to the flow-cell through the upper unit fitting.

In our experimental procedures, we have introduced different solutions into the flow-cell assembly that (among other protocols) provide exposure of encapsulated cells in beads to phosphorus and, subsequently, to selected heavy metals. Samples of beads can be extracted from the flowcell at any time during operations using a $10 \mathrm{ml}$ syringe attached to the main body sidearm. Samples that are prepared for microscopy can then be quickly injected under the surface of fixative solutions or into cryogenic media, allowing virtually no exposure of the specimens to air. As a consequence, structural organization and native cellular composition are kept to a minimum of alteration. The biosorption of phosphates (as an example) along with heavy metals, and their release under microaerophyllic conditions (by means of upwards flowing gaseous $\mathrm{N}_{2}$ through the medium for a designated period of time), can be determined through the use of techniques such as ICP, energydispersive X-ray microanalysis and spectrophotometric procedures, as well as the examination of specimens through the use of varied types of microscopy.
We have employed the use of the equipment described in this paper in evaluating the ability of the cyanobacterium, Plectonema boryanum, to sequester lead in inorganic polyphosphate bodies and to release the lead and phosphorus under microaerophyllic conditions. Details of this work are to be separately reported. High titers of $P$. boryanum were prepared in a phosphorus-rich medium and, after reaching stationary phase, were gently blended with a $5 \%$ sodium alginate solution until a uniform mixture was established. Beads, $1.5 \mathrm{~mm}$ in diameter were collected and suspended in a $\mathrm{CaCl}_{2}$ solution for $30 \mathrm{~min}$, and then washed $3 \mathrm{x}$ in distilled water as described above. Approx. $30 \mathrm{ml}$ of beads were then transferred to a flow-cell within a nutrient medium that lacked phosphorus. The flow-cell was recirculated with the medium for 18 hrs after which the medium with phosphorus was reintroduced along with 0.1 $\mathrm{mg} / \mathrm{l} \mathrm{PbCl}_{2}$ for a period of $1 \mathrm{hr}$. Within $5 \mathrm{~min}$, samples of beads with $P$. boryanum extracted from the flow-cell showed evidence of inorganic polyphosphate body formation. By $1 \mathrm{hr}$, the polyphosphate bodies containing $\mathrm{Pb}$ were numerous and ranged up to $1.0 \mu \mathrm{m}$ in diameter. The beads were then washed with a phosphorus-rich medium and subjected to microaerophyllic conditions by using an upwards dry nitrogen gas bubbling in the flow-cell for up to 24 hrs. Samples collected during this time were analyzed with ICP for the amount of phosphorus and lead per mg of

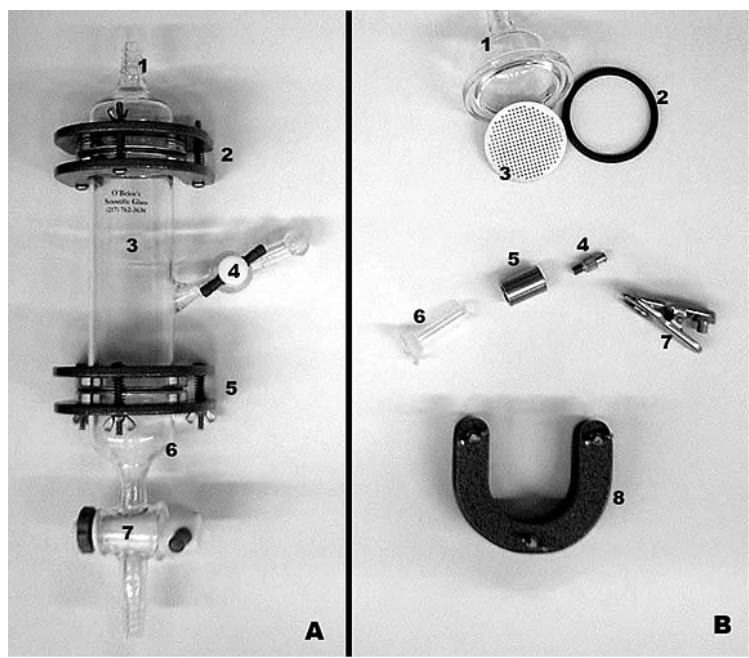

Figure 4. Flow-cell assembled and also showing some components.

(a) Assembled flow cell: 1) Top fitting for flow cell; 2) Upper horseshoe clamp for holding top fitting with flow-cell body; 3 ) Flow-cell central body; 4) Adjustable side-arm for the extraction of fluids and beads; 5) Lower horseshoe clamp for holding bottom fitting; 7) Adjustable valve for regulating flow and extraction of contents as well as allowing the upward flow of gasses such as $\mathrm{N}_{2}$ through the complete assembly.

(b) Expanded view of selected parts of flow-cell: 1) Top fitting for flow-cell; 2) O-ring between top fitting and main flow-cell body; 3) Aluminium filter designed to contain alginate beads, but to allow for liquid and gaseous flow; 4) Adapter fitting for LeurLoc $®$ syringe; 5) Glass-to-steel intermediate adapter; 6) Fitting with ground-glass flanged surface to attach to the side-arm of the central flow-cell body; 7) Clamp for holding the fitting onto the side-arm; 8) View of horseshoe clamp with three tightening screws. 


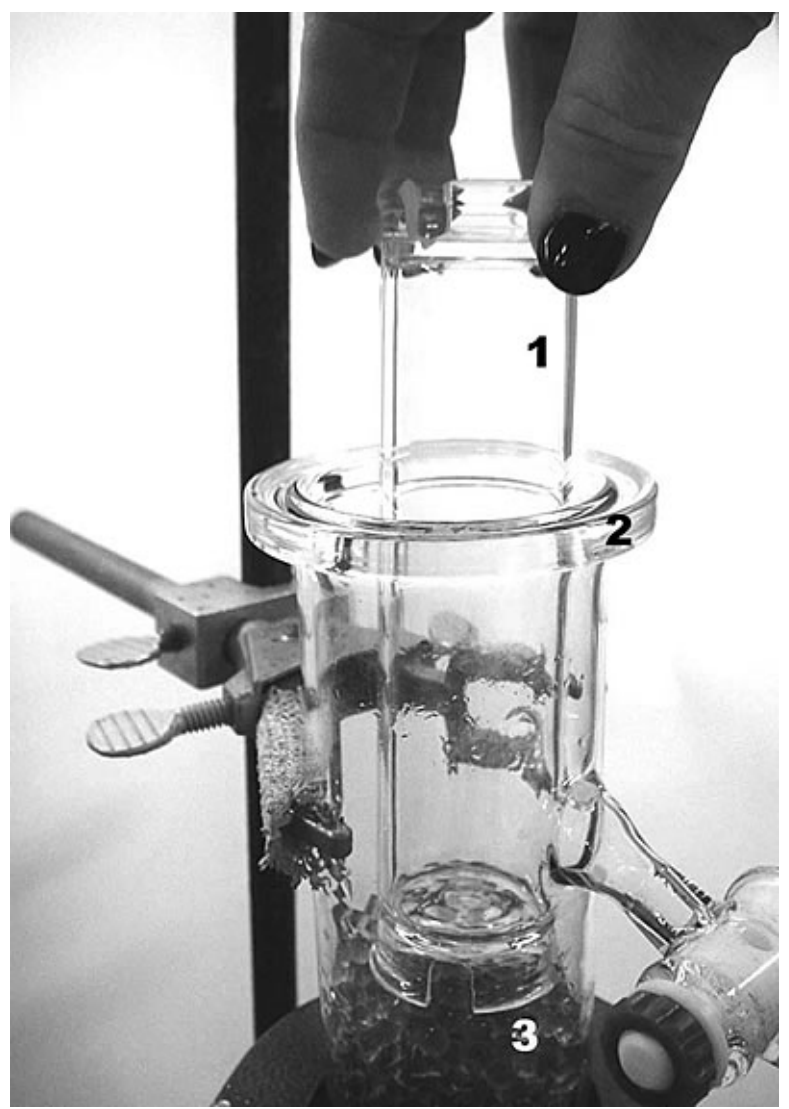

Figure 5. Insertion of a Pyrex® glass adaptor (1) into the flow-cell (2) with the top unit of the assembly removed. Alginate beads may be observed at the bottom of the assembly (3). The use of this adapter reduces the useful volume of the assembly to approx. $30 \mathrm{ml}$. Other sizes may be used.

beads. A 44\% reduction in the amount of phosphorus and a $27 \%$ reduction in the amount of lead per mg of beads was recorded by the end of 24 hrs. Additional studies are being conducted on the ability of $P$. boryanum to sequester and release other metals using the devices described in this report.

In our opinion the two pieces of equipment described in this paper offer a simple, economical and reliable means for conducting a variety of biological, biochemical and pharmaceutical research procedures involving studies on the encapsulation of biochemical, microbiological and/or cultured cellular components and their experimental use in biosorption and other applications.

In our opinion the two pieces of equipment described in this paper offer a simple, economical and reliable means for conducting a variety of biological, biochemical and pharmaceutical research procedures involving studies on the encapsulation of biochemical, microbiological and/or cultured cellular components and their experimental use in biosorption and other applications.
Equipment design for biosorption studies with microorganisms

\section{ACKNOWLEDGMENTS}

We wish to thank the technical assistance of M. Baxter, J. Goldberg and J. Hagan-Brown for testing the utilization of the equipment described in this paper.

\section{REFERENCES}

BASHAN, Yoav. Alginate beads as synthetic inoculant carriers for slow release of bacteria that affect plant growth. Applied and Environmental Microbiology, May 1986, vol. 51, no. 5, p. 1089-1098.

DE-BASHAN, Luz E.; HERNANDEZ, Juan-Pablo; MOREY, Taylor and BASHAN, Yoav. Microalgae growthpromoting bacteria as "helpers" for microalgae: A novel approach for removing ammonium and phosphorus from municipal wastewater. Water Research, 2003, vol. 38, no. 2, p. 466-474.

GONZALEZ, Luz E. and BASHAN, Yoav. Increased growth of the microalga Chlorella vulgaris when coimmobilized and cocultured in alginate beads with the plant-growth-promoting bacterium Azospirillum brasilense. Applied and Environmental Microbiology, April 2000, vol. 66, no. 4, p. 1527-1531.

HEALD, K.A.; JAY, T.R. and DOWNING, R. Assessment of the reproducibility of alginate encapsulation of pancreatic islets using the MTT colorimetric assay. Cell Transplantation, 1994, vol. 3, no. 4, p. 333-337.

HUGUET, M.L.; GROBOILLOT, A.; NEUFELD, R.J.; PONCELET, D. and DELLACHERIE, E. Hemolglobin encapsulation in chitosan/calcium alginate beads. Journal of Applied Polymer Science, February 1994, vol. 51, no. 8, p. 1427-1432.

KLOKK, T.I. and MELVIK, J.E. Controlling the size of alginate gel beads by use of a high electrostatic potential. Journal of Microencapsulation, July 2002, vol. 19, no. 4, p. 415-424.

LEE, Ki-Yong and HEO, Tae-Ryeon. Survival of Bifidobacterium longum immobilized in calcium alginate beads in simulated gastric juices and bile salt solution. Applied and Environmental Microbiology, February 2000, vol. 66, no. 2, p. 869-873.

MURASHIGE, T. and SKOOG, F. A revised medium for rapid growth and bioassays with tobacco tissue cultures. Physiologia Plantarum, 1962, vol. 15, no. 3, p. 473-497.

PREVIATI, A.; BENELLI, C.; DA RE, F.; DE CARLO, A.; VETTORI, C. and LAMBARDI, M. In vitro propagation and conservation of red chicory germplasm. In: International Meeting on: The Role of Biotechnology. $\left(5^{\text {th }}\right.$ $7^{\text {th }}$ March 2005, Turin, Italy). p. 207-208. 
Jensen, T.E. et al.

SERP, D.; CANTANA, E.; HEINZEN, C.; VON STOCKAR, U. and MARISON, I.W. Characterization of an encapsulation device for the production of monodisperse alginate beads for cell immobilization. Biotechnology and Bioengineering, October 2000, vol. 70, no. 1, p. 41-53.

WILDE, Edward W. and BENEMANN, John R. Bioremoval of heavy metals by the use of microalgae. Biotechnology Advances, 1993, vol. 11, no. 4, p. 781-812. 